\title{
The Importance of Communication during the Hiring Process as a Part of Global Recruitment Strategy
}

\author{
Dominika Gajdosikova ${ }^{1, *}$ \\ ${ }^{1}$ University of Zilina, Faculty of Operation and Economics of Transport and Communications, \\ Univerzitna 1, 01026 Zilina, Slovakia
}

\begin{abstract}
Research background: Human resources are known as one of the key factors. Every enterprise can address many candidates with the right abilities, knowledge, and skills within a quality hiring process and thus achieve sufficient performance in a globally competitive environment and its constant changes. The quality of the hiring process depends on the correct choice of the method of communication during its implementation.

Purpose of the article: The aim of this paper is to empirically test whether there is a statistically significant relationship between the level of management of the occupied job position and the way of communication of the personnel department and the candidate.

Methods: The input data, which were needed to test the hypothesis, were collected through a questionnaire survey conducted in the enterprise. Before testing the hypothesis, it was necessary to create a contingency table and then perform a chi-square test, which confirmed the existence of a relationship between the two monitored variables. The strength of the dependence was tested using the Cramer's V contingency coefficient and included a test of its statistical significance, too.

Findings \& Value added: The contingency coefficient reached the value of 0.542 , and, arguably, there is a medium dependence between the level of management of the occupied position and the way of communication of the personnel department and the candidate. It can be said that the contingency coefficient is statistically significant because the P-value is less than the significance level.
\end{abstract}

Keywords: human resources management; hiring process; communication; contingency coefficient

JEL Classification: $L 22 ; M 12 ; M 51$

\footnotetext{
* Corresponding author: dominika.gajdosikova@stud.uniza.sk
} 


\section{Introduction}

Human resources are an important factor in the production of any enterprise because they affect the use of other production factors, which are key for the security of the corporate business process (Gajanova et al., 2020). The human resources management of each enterprise determines the appropriate relationship between the employee's work and his satisfaction (Jedrzejczak-Gas and Wyrwa, 2020). It is important for the enterprise to ensure the overall satisfaction of employees at work and to identify the factors that may lead to early termination of employment (Pekersen and Tugay, 2020).

In today's world, which is constantly changing due to globalization, enterprises must employ employees with professional knowledge who see a new opportunity for further personal development during performing a work activity (Stofkova and Sukalova, 2020). Every enterprise responds flexibly to changes affected by globalization and thus adapts to the market needs. The current situation also affects the development of human resource management. If an enterprise wants to succeed in the competition, it must use new ways, methods, and approaches in human resource management. These employees are considered to be a source of the enterprise's competitiveness (Sukalova and Ceniga, 2020).

The overall management of human resources has become the bearer of the enterprise's strategy and requires a qualified approach to their comprehensive management. All related personnel activities are in the competence of the enterprise's personnel department, which is also responsible for education (Gavurova et al., 2021) and R\&D (Ionescu, 2020), related to drivers of technological change (Kovacova et al., 2020; Stefko et al., 2019). All recruitment activities in the enterprise follow the process of personnel planning and include recruiting, selecting, hiring, and adapting new employees. The purpose of recruiting new employees is to attract several suitable candidates for the occupied job position. The important part of this process is to define the requirements of the occupied job position and the choice of appropriate resources and communication methods of the process (Joniakova et al., 2016).

Ensuring a smooth and efficient hiring process is the main purpose of every enterprise. Choosing the right way of communication is a key element of its course in today's globalized world. In the case of filling a job at the international level, the choice of the way of communication is an important part of the process (Karacsony et al., 2020). Currently, the most common ways of communication are communication by telephone or e-mail. The main purpose of the article is to verify whether the choice of the way of communication depends on the level of management of the occupied job position (whether there is a dependence between the monitored variables).

The paper is divided into the following sections: in the first part, the reader is familiar with the basic theoretical background of the problem through a literature review. The second part describes suitable methods for meeting the objective of this paper, which is to verify the existence of the dependence. The third part is focused on the description of the results obtained in the questionnaire survey in the enterprise, and the subsequent testing of the existence of the relationship between two categorical variables. The fourth part summarizes the results obtained from the previous analysis of the researched issues.

\section{Literature Review}

In the professional literature and the business environment, it is possible to encounter various concepts related to human resource management in the enterprise, such as personnel work, personnel administration, personnel management, human resources management, personnel management, human resources management, or even intellectual capital management.

Human resource management is an activity considered to be the heart of every successful enterprise in the market. If an enterprise wants to be successful in the market, it must realize 
the importance of the value of human resources. People are the main essence of any enterprise, and their management depends on how the enterprise succeeds in the market. However, the importance of human resource management is decided by the enterprise itself. It also decides on the scope and position of human resources management in the enterprise. At present, human resource management has a different position. It includes many activities, such as planning, recruitment, selection, training, and development. It also focuses on the activities of improving working conditions in the enterprise to eliminate possible employee turnover (Pace et al., 2021).

Predetermined goals can be achieved by the enterprise using coordinated human activity, which is primarily involved in the movement of other factors of production of the enterprise (Ivanov and Usheva, 2021; Stefko et al., 2020).

Other factors of production of the enterprise include machinery, apparatus, equipment, finance, as well as information (Horvathova Suleimanova et al., 2019). These days, enterprises face challenges that are related to human resource management. The goal of every enterprise is to employ highly qualified employees, who can be considered as a source of competitive advantage for the enterprise, and to whom the enterprise can provide various qualified training courses (Krisnaresanti et al., 2020).

There are three basic concepts associated with human resource management: human resources, human capital, and human potential. Human resources are characterized as a key factor in the success of an enterprise. The quality of the produced products depends on the employee's abilities, which are involved in the individual production processes (GarciaAlcaraz et al., 2019). Human capital is characterized as a set of professional skills combined with the creativity and initiative of every working person in the enterprise, which participates in generating profit (Lazarov, 2020). The next concept is human capital. Human capital is one of the main determinants of economic growth, which is an important part of the country's technological progress. Especially, soft skills are part of human capital, and these are currently in great demand in the labor market, such as communication and organizational skills. These skills are being developed in non-formal education institutions (Souto-Otero, 2016). The last concept is human potential. Human potential is defined as the most important factor, which is in its essence unique. It is largely influenced by genetics and includes talents that characterize human abilities under normal circumstances and characteristics that describe human character traits (Latova, 2019). Overall evaluation of human resources, human capital, and human potential is considered to be the most important challenge in any type of enterprise (Litvinenko et al., 2019).

The hiring process of employees is a key process in every enterprise, and it is largely described as the most important. The process takes place in the labor market between the seller and the buyer - i.e. the employee and the employer (Bratton and Gold, 2017). Many definitions in the professional literature can be related to the hiring process. The hiring process is the process of finding, evaluating, and selecting a new employee. In the case of filling a job at the international level, the process is more complicated because it is necessary to take into account other factors, such as language barriers or different cultures. The current concept of human resource management explains that the hiring process is not just about getting the required number of employees. It is also about getting employees who identify with the enterprise, its values, and its culture (Mutudi and Iyamu, 2018). The hiring process is a part of a global recruitment strategy, that is significantly influenced not only by the enterprise's internal conditions, but also by the external environment. Every enterprise needs to anticipate and react flexibly to changes in the labor market, eliminate possible threats and take advantage of opportunities to meet the current and future needs of the enterprise. The main role of human resources managers during the hiring process is to decide on possible ways of communication and at the same time to respect the principles not only from an 
economic but also a social point of view. Each enterprise has a choice of two basic ways of communication - via e-mail and telephone (Vetrakova et al., 2018).

In general, the hiring process is a financially and time-consuming process. It is important to devote sufficient time and money to it. An effective hiring process is a step-by-step process that takes a relatively long time to find the most suitable employee for the enterprise.

\section{Methods}

It was necessary to carry out a questionnaire survey in the enterprise to successfully evaluate a predetermined hypothesis.

The questionnaire survey contained 20 questions and consisted of two parts. The first part of the questionnaire consisted of elementary identification data of individual respondents, such as gender, age, education, number of months of work in the enterprise. The second part of the questionnaire was focused on the course of the hiring process in the enterprise. The answers of the respondents in the enterprise were collected for two weeks. A total of 122 respondents took part in the survey, with a return percentage of $96.82 \%$.

The dependence between two categorical variables, at least one of which has more than two variations, is called contingency. The data obtained from the survey must be arranged in a contingency table. The contingency table is a combination of different characteristics that define each category of individual rows and columns (de Toledo et al., 2018).

Hypotheses about the existence of a relationship between two qualitative variables are tested using the Pearson chi-square test, which is preceded by the creation of the contingency table itself. The Pearson chi-square test is a test, which its main task is to determine whether or not there is a statistically significant relationship between the two observed variables. If there is a statistically significant dependence between two variables, the strength of the relationship between them can be measured using a contingency coefficient that takes values from 0 to 1 (Warchol et al., 2021). In the case of confirmation of dependence by Pearson chisquare test, the most commonly used contingency coefficient is the Cramer's V coefficient. In general, if the coefficient takes values from 0 to 0.3 , it is a weak dependence. If the coefficient is in the range of 0.3 to 0.8 , it is a moderately strong dependence. If the coefficient is higher than 0.8 , it is a strong dependence between the two categorical variables. As part of the interpretation of the strength of dependence between variables, it is necessary to verify its statistical significance (McHugh, 2013).

The analysis was performed in the following methodological steps:

1. After completing the questionnaire survey, individual samples of respondents were analysed, and then contingency tables were created.

2. To use the Pearson chi-square test, the following conditions were verified: for a contingency table that has been created with a size of $\mathrm{c}$ x r $(\mathrm{c}=$ number of columns, $\mathrm{r}=$ number of rows), at least $80 \%$ of the theoretical frequencies must be greater than or equal to 5 and at the same time none of them must be zero.

3. At a significance level of $5 \%$, it was necessary to test for the existence of a relationship between the two monitored variables $\mathrm{X}$ and $\mathrm{Y}$.

4. The strength of the dependence between the two monitored variables was verified using Cramer's V, and the statistical significance was also confirmed using the contingency coefficient.

\section{Results}

In the enterprise we monitored, which has 596 employees, 122 respondents took part in the survey. Its main task was to address a sufficient number of respondents and obtain essential information on the method of communication between the enterprise's personnel department 
and the potential candidate. The elementary identification data of the participating respondents, such as gender, age, education, number of months of work in the enterprise, are summarized in Table 1.

Table 1. The elementary data of the participating respondents.

\begin{tabular}{llcc}
\hline Indicator & & Absolute Frequency & Relatively Frequency \\
\hline Gender & male & 45 & 36.89 \\
& female & 77 & 63.11 \\
\hline Age & $18-29$ & 6 & 4.92 \\
& $30-39$ & 57 & 46.72 \\
& $40-49$ & 40 & 32.79 \\
& $50-59$ & 19 & 15.57 \\
\hline Education & primary & 9 & 7.38 \\
& high school graduate & 74 & 60.66 \\
& Bachelor's degree & 4 & 3.28 \\
& Master's degree & 26 & 21.30 \\
& Doctorate degree & 9 & 7.38 \\
\hline Number of & less than 3 & 6 & 4.92 \\
months of work & $3-12$ & 17 & 13.93 \\
in the enterprise & $12-36$ & 36 & 29.51 \\
& more than 36 & 63 & 51.64 \\
\hline Total & & $\mathbf{1 2 2}$ & $\mathbf{1 0 0 . 0 0}$ \\
\hline
\end{tabular}

Source: own processing based on a questionnaire survey

In the questionnaire survey, we examined the level of management of the respondents within their performed job position. The answers of the respondents involved in the questionnaire survey are shown in Table 2. The most numerous group of respondents are respondents from employees working in production because 67 of them participated in the questionnaire survey. The following are middle-level management respondents who participated in the questionnaire survey 33. The 16 respondents who participated in the questionnaire survey belong to the low-level management level, and the smallest group are top-level management respondents because 6 of them participated in the questionnaire survey in the enterprise.

Table 2. The level of management of the participating respondents.

\begin{tabular}{lcc}
\hline & Absolute Frequency & Relatively Frequency \\
\hline top-level management & 6 & 4.92 \\
middle-level management & 33 & 27.05 \\
low-level management & 16 & 13.11 \\
workers & 67 & 54.92 \\
\hline Total & $\mathbf{1 2 2}$ & $\mathbf{1 0 0 . 0 0}$ \\
\hline
\end{tabular}

Source: own processing based on a questionnaire survey

In the questionnaire survey, we also found out how the enterprise's personnel department contacted suitable candidates who have succeeded in the previous process. The answers of the individual respondents involved in the questionnaire survey are shown in Table 3. The 
64 respondents were contacted by telephone within the hiring process. The 54 respondents stated that the enterprise's personnel department contacted them via e-mail. In the questionnaire survey, respondents had the opportunity to choose the way of communication via the post office, but no respondent provided this answer.

Table 3. The way of communication between the personnel department and the suitable candidates of the participating respondents.

\begin{tabular}{lcc}
\hline & Absolute frequency & Relatively Frequency \\
\hline via telephone & 68 & 55.74 \\
via e-mail & 54 & 44.26 \\
via the post office & 0 & 0.00 \\
\hline Total & $\mathbf{1 2 2}$ & $\mathbf{1 0 0 . 0 0}$ \\
\hline
\end{tabular}

Source: own processing based on a questionnaire survey

The main aim of this paper was to verify whether there is a statistically significant dependence between the level of management of the respondents and the way of communication of the personnel department and the potential candidates.

During testing the hypothesis, it was necessary to process pairs of qualitative (verbal) variables using a contingency table and then use the chi-square test to evaluate the existence of dependence between the variables. A contingency table of empirical and theoretical frequencies of monitored variables was created in the first step. The 2 cells of the created contingency table did not meet the condition for testing because their theoretical frequency is less than 5. In the next step, the variables top-level management and middle-level management were merged into one category, which is logically created for further calculation, and then re-created contingency table of empirical and theoretical frequencies (Table 4).

Table 4. Contingency table of empirical and theoretical frequencies.

\begin{tabular}{lllccc}
\hline & & & \multicolumn{3}{c}{ the way of communication } \\
& & & via \\
& & & 36 & via \\
telephone & Total \\
\hline the level of & top-level and middle-level & Count & 3 & 39 \\
management & management & Expected Count & 18.2 & 20.8 & 39.0 \\
& low-level management & Count & 12 & 4 & 16 \\
& \multirow{2}{*}{ workers } & Expected Count & 7.5 & 8.5 & 16.0 \\
& & Count & 42 & 25 & 67 \\
& & Expected Count & 31.3 & 35.7 & 67.0 \\
\hline Total & Count & 57 & 65 & 122 \\
& & Expected Count & 57.0 & 65.0 & 122.0 \\
\hline
\end{tabular}

Source: own processing based on a questionnaire survey

The result of the chi-square test is shown in the following table (Table 5). It is necessary to establish hypotheses to evaluate the test. The null hypothesis $\mathrm{H}_{0}$ states, that there is no dependence between the level of management and the way of communication between the personnel department and the potential candidate. The alternative hypothesis $\mathrm{H}_{1}$ states that there is a dependence between the level of management and the method of communication. The chosen level of significance $\alpha$ is $5 \%$. 
Table 5. Chi-square test results.

\begin{tabular}{lccc}
\hline & Value & df & $\begin{array}{c}\text { Asymptotic } \\
\text { Significance (2-sided) }\end{array}$ \\
\hline Pearson Chi-Square & $35.866^{\mathrm{a}}$ & 2 & 0.000 \\
Likelihood Ratio & 40.935 & 2 & 0.000 \\
N of Valid Cases & 122 & & \\
\hline a. 0 cell $(0.00 \%)$ have expected count less than 5. The minimum expected count is 7.48.
\end{tabular}

Source: own processing based on a questionnaire survey

The P-value of the test is less than the chosen level of significance $\alpha$, so we reject the null hypothesis $\mathrm{H}_{0}$ and accept the alternative hypothesis $\mathrm{H}_{1}$, whose statement is that there is a relationship between the level of management and the method of communication.

Because there is a dependence between the two monitored variables, it is possible to interpret the strength of the dependence between them using the Cramer's V coefficient from Table 6 and at the same time its statistical significance. Hypotheses are needed to evaluate the statistical significance of the coefficient. The null hypothesis $\mathrm{H}_{0}$ states that the Cramer's $\mathrm{V}$ coefficient is not statistically significant. The null hypothesis $\mathrm{H}_{0}$ is opposed by the alternative hypothesis $\mathrm{H}_{1}$, which states that the Cramer's $\mathrm{V}$ coefficient is statistically significant. The chosen level of significance $\alpha$ is again $5 \%$.

Table 6. Values of contingency coefficient Cramer's V.

\begin{tabular}{llcc}
\hline & & Value & $\begin{array}{c}\text { Approximate } \\
\text { Significance }\end{array}$ \\
\hline Nominal by Nominal & Phi & 0.542 & 0.000 \\
& Cramer's V & 0.542 & 0.000 \\
N of Valid Cases & & 122 & \\
\hline
\end{tabular}

Source: own processing based on a questionnaire survey

Based on the Cramer's V contingency coefficient, which reaches 0.542 , it can be argued that there is a moderate dependence between the variables. The statistical significance of the contingency coefficient can be evaluated using the $p$-value of the test. Because the p-value of the test is less than the chosen level of significance $\alpha$, we reject the null hypothesis $\mathrm{H}_{0}$ and accept the alternative hypothesis $\mathrm{H}_{1}$, which states that the Cramer's V contingency coefficient is statistically significant.

\section{Discussion}

When interpreting the result, it can be argued that the choice of the way of communication largely depends on the level of management belonging to the occupied job position. From the created contingency table, it is clear that the personnel department of the enterprise contacts the applicants for the job position of the middle-level and top-level management by telephone, while for the applicants, who apply for the job position corresponding to the lowlevel management level, the personnel department prefers communication via e-mail. It can be stated that applicants corresponding to the workers are contacted by the enterprise's personnel department by e-mail.

Although, the e-mail communication has considerable advantages, such as its simplicity, speed, and removal of the distance and time barrier, it also has significant disadvantages. The biggest disadvantages of communication via e-mail can be considered the austerity of written expression and the lack of an emotional component, which can also result in a misunderstanding of e-mail. 
Compared to e-mail communication, telephone communication is considered to be a more personal form that is flexible and relatively secure. A telephone call is generally the most effective form of communication and is also an effective way for conversation between the personnel department of the enterprise and a suitable candidate to inform him about the success.

It is obvious that due to time optimization, the enterprise uses communication via e-mail during the hiring process of a job position that belongs to low-level management. Job positions at low-level management are associated with higher staff turnover. Therefore it is necessary to use such a way of communication during the hiring process, which will make the work easier for the human resources specialist. It is also clear that the job positions at low-level management jobs do not require high demands on the candidate's abilities and skills.

On the other hand, during the hiring process of a job position that belongs to mediumlevel or top-level management, the enterprise uses telephone communication. The human resources specialist thus contacts candidates who meet the requirements for the occupied job position and who have successfully passed the selection process exclusively by telephone. The telephone call allows the human resources specialist to have a two-way dialogue with the candidate. This type of communication will ensure that the information provided is immediately understood by both parties involved. This two-way dialogue also allows the human resources specialist to feel more active during the communication and is also able to react immediately during the dialogue.

\section{Conclusion}

The issue of human resources management is a current topic because human resources are considered an essential resource in every enterprise. Employees are an inexhaustible resource in the enterprise that must be constantly improved with other resources. For this reason, the successful implementation of the hiring process is an important part of corporate management, which is also related to the selection of a suitable way of communication between the enterprise's personnel department and a suitable candidate. As a result, it can be argued that the choice of the way of communication largely depends on the level of management belonging to the occupied job position. It can be argued that there is a moderate dependence between the two monitored variables, and the enterprise chooses a way of communication depending on the level of management of the occupied job position. The main limitation of this paper was the examination of the course of the process within one international enterprise. This limitation can be eliminated by examining the process within a specific industry, which can be part of subsequent research.

\section{References}

1. Bratton, J., Gold, J. (2017). Human Resources Management. Macrimilian Publishers.

2. de Toledo, P. A., Nunez, F., \& Usabiaga, C. (2018). Matching and clustering in square contingency tables. Who matches with whom in the Spanish labour market. Computational Statistics \& Data Analysis, 127, 135-159.

3. Gajanova, L., Nadanyiova, M., Musat, M., \& Bogdan, A. (2020). The social recruitment as a new opportunity in the Czech Republic and Slovakia. Economic and Managerial Spectrum, 14(1), 65-77.

4. Garcia-Alcaraz, J. L., Flor-Montalvo, F. J., Avelar-Sosa, L., Sánchez-Ramírez, C., \& Jiménez-Macías, E. (2019). Human resource abilities and skills in TQM for sustainable enterprises. Sustainability, 11(22). Article 6488. 
5. Gavurova, B., Belas, J., Zvarikova, K., Rigelský, M., \& Ivankova, V. (2021). The effect of education and R\&D on tourism spending in OECD countries: An empirical study. Amfiteatru Economic, 23(58), 806-823.

6. Horvathova Suleimanova, J., Wojcak, E., \& Polakova, M. (2019). Vzdelavanie a rozvoj zamestnancov. Elfa.

7. Ionescu, L. (2020). Robotic process automation, deep learning, and natural language processing in algorithmic data-driven accounting information systems. Analysis and Metaphysics, 19, 59-65.

8. Ivanov, P., \& Usheva, M. (2021). Workplace outcomes, the example of Bulgarian corporations. Economic and Managerial Spectrum, 15(1), 84-97.

9. Joniakova, Z., Galik, R., Blstakova, J., \& Tariskova, N. (2016). Riadenie ludskych zdrojov. Wolters Kluwer.

10. Jedrzejczak-Gas, J., \& Wyrwa, J. (2020). Determinants of job satisfaction in a transport company: a Polish case study. Equilibrium. Quarterly Journal of Economics and Economic Policy, 15(3), 565-593.

11. Karacsony, P., Izsak, T., \& Vasa, L. (2020). Attitudes of Z generation to job searching through social media. Economics \& Sociology, 13(4), 227-240.

12. Kovacova, M., Segers, C., Tumpach, M., \& Michalkova, L. (2020). Big Data-driven Smart Manufacturing: Sustainable Production Processes, Real-Time Sensor Networks, and Industrial Value Creation. Economics, Management \& Financial Markets, 15(1), 54-60.

13. Krisnaresanti, A., Julialevi, K. O., Naufalin, L. R., \& Dinanti, A. (2020). Analysis of Entrepreneurship Education in Creating New Entrepreneurs. International Journal of Entrepreneurial Knowledge, 8(2), 67-76.

14. Latova, N. (2019). Leisure Practices of Russian Employees as a Factor of Their Human Potential Formation. Sotsiologicheskie issledovaniya, 11, 63-72.

15. Lazarov, A. S. (2020). The importance of human capital and the human organization management in a crisis situation. Proceedings of the International Conference on Business Excellence, 14(1), 906-914.

16. Litvinenko, A., Litvinenko, N., \& Mamyrbayev, O. (2019). Application of Bayesian networks for estimation of individual psychological characteristics. Przelglad elektrotechniczny, 95(5), 92-97.

17. McHugh, M. L. (2013). The chi-square test of independence. Biochemia medica, 23(2), 143-149.

18. Mutudi, M., \& Iyamu, T. (2018). Virtual team development of a web-based recruitment system for an iD-lab. Education and Information Technologies, 23(5), 1955-1970.

19. Pace, F., Ingusci, E., Signore, F., \& Sciotto, G. (2021). Human Resources Management Practices Perception and Extra-Role Behaviors: The Role of Employability and Learning at Work. Sustainability, 13(16). Article 8803.

20. Pekersen, Y., Tugay, O (2020). Professional Satisfaction as a Key Factor in Employee Retention: A case of the Service Sector. Journal of Tourism and Services, 20(11), 1-27.

21. Souto-Otero, M. (2016). Young people's views of the outcomes of non-formal education in youth organisations: its effects on human, social and psychological capital, employability and employment. Journal of Youth Studies, 19(7), 938-956.

22. Stefko, R., Bacik, R., Fedorko, R., Olearova, M., \& Rigelsky, M. (2019). Analysis of consumer preferences related to the use of digital devices in the e-commerce dimension. Entrepreneurship and Sustainability Issues, 7(1), 25-33. 
23. Stefko, R., Fedorko, R., Bacik, R., Rigelsky, M., \& Olearova, M. (2020). Effect of service quality assessment on perception of TOP hotels in terms of sentiment polarity in the Visegrad group countries. Oeconomia Copernicana, 11(4), 721-742.

24. Stofkova, Z., \& Sukalova, V. (2020). Sustainable development of human resources in globalization period. Sustainability, 12(18). Article 7681.

25. Sukalova, V., \& Ceniga, P. (2020). Diversity Management in Sustainable Human Resources Management. SHS Web of Conferences, 74, The 19th International Scientific Conference Globalization and its Socio-Economic Consequences 2019 - Sustainability in the Global-Knowledge Economy, Article 01033.

26. Vetrakova, M., Hitka, M., Potkany, M., Lorincova, S., \& Smerek, L. (2018). Corporate sustainability in the process of employee recruitment through social networks in conditions of Slovak small and medium enterprises. Sustainability, 10(5). Article 1670.

27. Warchoł, K., Korobeynikov, G., Osiel, C., \& Cynarski, W. J. (2021). Martial arts as a form of physical activity for children and young people in the opinion of adult inhabitants of Podkarpackie Voivodeship. Ido Movement for Culture. Journal of Martial Arts Anthropology, 21(1), 28-37. 